\title{
Effect of Tilmicosin on Fetal Developments in Pregnant Female Albino Rats
}

\author{
Seham Abo-Kora, Amany El-Meleh, Mohamd Aboubakr* \\ Department of Pharmacology, Faculty of Veterinary Medicine, Benha University, Toukh, Egypt \\ Email: "mohamed.aboubakr@fvtm.bu.edu.eg
}

Received 1 March 2016; accepted 17 April 2016; published 20 April 2016

Copyright @ 2016 by authors and Scientific Research Publishing Inc.

This work is licensed under the Creative Commons Attribution International License (CC BY). http://creativecommons.org/licenses/by/4.0/

(c) (;) Open Access

\begin{abstract}
The effect of tilmicosin on fetal development in pregnant female rats was investigated in this study. Forty pregnant female rats were divided into four groups (each of 10 female rats). Rats in the 1st, 2nd and 3rd groups were received tilmicosin at a dose of $20,100,200 \mathrm{mg} / \mathrm{kg} \cdot \mathrm{b} \cdot \mathrm{wt} / \mathrm{day}$ orally from the 6th to 15 th day of gestation respectively, while the 4th group received $0.5 \mathrm{ml}$ distilled water orally for the same period of gestation and was used as control group. All the pregnant female rats were sacrificed on the 20th day of gestation and their fetuses were subjected to morphological, visceral and skeletal examinations. Tilmicosin at a dose $100,200 \mathrm{mg} / \mathrm{kg} \cdot \mathrm{b} \cdot \mathrm{wt}$ significantly decreased the number of viable fetuses; the number of resorbed fetuses was increased, and induced retardation in growth of viable fetuses; some skeletal and visceral defects in these fetuses were observed and these effects were dose dependant. It could be concluded that tilmicosin caused some abnormalities and fetal defects, so it is recommended to avoid using pregnancy.
\end{abstract}

\section{Keywords}

Tilmicosin, Pregnancy, Anomalies, Fetus

\section{Introduction}

Macrolide antibiotics are frequently used for presumed or documented Gram-positive lower and upper respiratory infections, Helicobacter pylori-related peptic ulcer and soft tissue infections. Moreover, for the treatment of chlamydia and other selected infections in pregnancy [1], macrolide antibiotics are the second most frequently used antibacterial class during pregnancy [2] [3]. It has excellent in vitro activity which is reported for Gram-positive bacteria and mycoplasma, and also for certain Gram-negative microbes such as Actinobacillus pleuropneumoniae, Pasteurella bemolytica, and Pasteurella multocida [4]. It is approved for treatment of bo-

${ }^{*}$ Corresponding author. 
vine respiratory disease (shipping fever associated with P. bemolytica and P. multocida) at a dosage level of 10 $\mathrm{mg} / \mathrm{kg}$ injected subcutaneously [5] [6].

Most therapeutic agents cross placental barrier and enter the circulation of fetus. Every drug given during pregnancy has tendency to produce some sort of structural abnormalities in the neonate [7]. The most critical period for malformation to take place is the period of organogenesis. Drugs given in this period are more likely to induce birth defects. This critical time of fetal developments in rats and mice is from $6-12$ days of their gestation [8].

The study of abnormal prenatal development and congenital malformations caused by physical agents or exogenous chemical is a growing area of medical research in the quest for the eradication of preventable birth defects. Defects of birth are known to occur in large numbers; roughly $7 \%$ to $10 \%$ of all children require an extensive health care to diagnose or treat a birth defect; this compromises the quality of life of millions of people worldwide [9]. A birth defect or a congenital malformation is a structural abnormality of any type present at birth, which may be macroscopic or microscopic, on the surface or within the body [10]. The aim of this study was to investigate the influence of tilmicosin on the fetal development in the organogenesis period in albino rats.

\section{Materials and Methods}

\subsection{Drug}

Tilmicosin (TILMI 25\% ®) in the form of water solution contains tilmicosin as tilmicosin phosphate $250 \mathrm{mg} / \mathrm{ml}$, manufactured by KEPRO B.V, Holland.

\subsection{Animals}

The experiment was carried out on forty mature healthy female Wister albino rats. The used rats were $8-10$ months and 210 - $250 \mathrm{gm}$, obtained from animal mouse colony of faculty of Veterinary Medicine Benha University. Animals were kept under hygienic conditions and fed on balanced ration and water ad libitum. Female rats were examined periodically using vaginal smear test to ensure that they were always in a regular estrous cycle [11]. They were kept with normal healthy male albino rats allowing one male for two female rats in one cage overnight [12]. The presence of sperms in the vagina next morning was considered as the first day of pregnancy [13]. Pregnancy was confirmed by persistence of diestrum state for 5 days after mating.

\subsection{Experimental Design}

The pregnant rats were divided into four groups each of 10 rats. Rats were given timicosin orally from the 6 th to 15th days of gestation.

1) The 1 st group received timicosin orally at a dose of $20 \mathrm{mg} / \mathrm{kg} \cdot \mathrm{b} \cdot \mathrm{wt} / \mathrm{day}$.

2) The 2nd group received timicosin orally at a dose of $100 \mathrm{mg} / \mathrm{kg} \cdot \mathrm{b} \cdot \mathrm{wt} /$ day.

3) The 3rd group received timicosin orally at a dose of $200 \mathrm{mg} / \mathrm{kg} \cdot \mathrm{b} \cdot \mathrm{wt} / \mathrm{day}$.

4) The 4th group received $0.5 \mathrm{ml}$ of distilled water orally for the same period, behaved as control group.

All females were killed on the 20th day of pregnancy and their uteri were dissected in order to examine the position and number of viable, resorbed, or dead fetuses. The surviving fetuses were weighed and the length from crown to rump was measured and examined for any external gross malformations, while others were stained by alizarin red for skeletal examination [14].

\subsection{Statistical Analysis.}

The obtained results from the experiment were expressed as mean \pm SEM and were analyzed by using SPSS program (one way ANOVA). Differences were declared significant at $\mathrm{P}<0.05$.

\section{Results}

The obtained results indicated that oral administration of tilmicosin from the 6th to 15 th day of pregnancy produced significant decrease in number of viable fetuses; fetal body weight and length were shown in Table 1. Visceral abnormalities following administration of tilmicosin were shown in Table 2. There was pulmonary hy- 
Table 1. Effect of Tilmicosin on number of viable fetuses, dead fetuses, fetal body weight and length obtained from pregnant female rats after oral administration of 20,100 , and $200 \mathrm{mg}$ tilmicosin/ $\mathrm{kg} \cdot \mathrm{b} \cdot \mathrm{wt}$ from the 6 th to 15 th day of pregnancy once daily $(\mathrm{n}=10)$.

\begin{tabular}{|c|c|c|c|c|c|}
\hline Animal group & $\begin{array}{c}\text { Number of viable } \\
\text { fetuses } \\
\mathrm{X} \pm \text { S.E }\end{array}$ & $\begin{array}{c}\text { Number of resorbed } \\
\text { fetuses } \\
\mathrm{X} \pm \text { S.E }\end{array}$ & $\begin{array}{c}\text { Number of dead } \\
\text { fetuses } \\
X \pm \text { S.E }\end{array}$ & $\begin{array}{c}\text { Fetal body weight (g) } \\
\text { X } \pm \text { S.E }\end{array}$ & $\begin{array}{c}\text { Fetal body length }(\mathrm{cm}) \\
\quad \mathrm{X} \pm \text { S.E }\end{array}$ \\
\hline 1st group & $9.30 \pm 0.300$ & - & - & $4.70 \pm 0.052^{*}$ & $3.48 \pm 0.053^{*}$ \\
\hline 2nd group & $7.40 \pm 0.699^{*}$ & - & - & $3.93 \pm 0.019^{*}$ & $3.56 \pm 0.052^{*}$ \\
\hline 3rd group & $3.30 \pm 0.948^{*}$ & $2.1 \pm 0.6$ & - & $3.09 \pm 0.054^{*}$ & $2.81 \pm 0.047^{*}$ \\
\hline 4th group & $9.2 \pm 0.326$ & - & - & $4.98 \pm 0.047$ & $4.45 \pm 0.062$ \\
\hline
\end{tabular}

${ }^{*} \mathrm{P}<0.05$.

Table 2. Visceral abnormalities in fetuses obtained from pregnant female rats after oral administration of 20, 100, and 200 $\mathrm{mg}$ tilmicosin $/ \mathrm{kg} \cdot \mathrm{b} \cdot \mathrm{wt}$ from the 6 th to 15 th day of pregnancy once daily $(\mathrm{n}=10)$.

\begin{tabular}{cccc}
\hline Parameters & 1st group & 2nd group & 3rd group \\
\hline Number of examined fetuses & 24 & 24 & 24 \\
Lung hypoplasia & - & $3(12.5 \%)$ & $5(20.83 \%)$ \\
Heart enlargement & - & $4(16.66 \%)$ & $6(25 \%)$ \\
Brain diverticulum & - & $6(25 \%)$ & $6(25 \%)$ \\
Thymus hypoplasia & - & $5(20.83 \%)$ & $7(29.16 \%)$
\end{tabular}

$\%$ : percent of total abnormalities in relation to the number of examined fetuses.

poplasia with cardiac enlargement Figure 1(a), diverticulum dilatation Figure 1(b) and there was hypoplasia in thymus as shown in Figure 1(c), also skeletal examination of examined fetuses showed impaired ossification of skull with small size of sternbrea Figure 1(d) with absence of digital bone of fore limb with rudentry ribs Figure 1(e) and absence of caudal vertebrae Figure 1(f) as shown in Table 3.

\section{Discussion}

Oral administration of tilmicosin in doses $(100$ and $200 \mathrm{mg} / \mathrm{kg} \cdot \mathrm{b} \cdot \mathrm{wt})$ to female pregnant rats induced significant decrease in the number of viable fetuses/mother when compared with control group without any fetal death. Significant decrease in number of feti/mother might be attributed to the lack of oval production or of the basic cell constituent as a result of drug administration [15]. This result might be attributed to the direct toxic action of the tilmicosin on the early developed fertilized ovum and this result was agree with [16], after oral administration of tiamulin in therapeutic and double therapeutic dose (36 and $72 \mathrm{mg} / \mathrm{kg} \cdot \mathrm{b} \cdot \mathrm{wt})$.

Significant increase in the number of resorbed fetuses in the present study might be attributed to the interference of tilmicosin with the placental transmission of leucin amino acid and magnesium as deficiency of leucin or magnesium produced high incidence of fetal resorptions [15], according to the relationship between parathyroid hormone secretion (PTH) and magnesium deficiency in which that an acute stimulation of PTH secretion induced by magnesium is characteristic of the magnesium-deficient state. The consistency of this response suggests that impaired PTH secretion is a significant factor contributing to the hypocalcemia of magnesium deficiency, which lead to fetal deformity either in the growth or bone formation, this result agree with [17] who reported marked increase in number of resorbed fetuses following administration of Bryostatin-1, a macrolide antibacterial agent to pregnant rats.

Administration of tilmicosin to female pregnant rats during the period of organogenesis produced significant decrease in both weight and length of fetuses. This result was consistent with [18] following administration of tilmicosin in rabbits. Presence of significant decrease in all growth and developmental parameters followes administration of macrolides in cultured rat embryos dose dependently [19]. The recorded reduction in fetal weight and length which resulted after oral administration tilmicosin might be attributed to the disturbance in metabolism of some minerals as magnesium and zinc in fetus, or to the interference of the drug to the placental transmission of magnesium and zinc from the mother to the fetus [15] as deficiencies of magnesium and zinc induced retardation of the fetal growth that which increase the fetal resorption and high rate of embryonic death. 

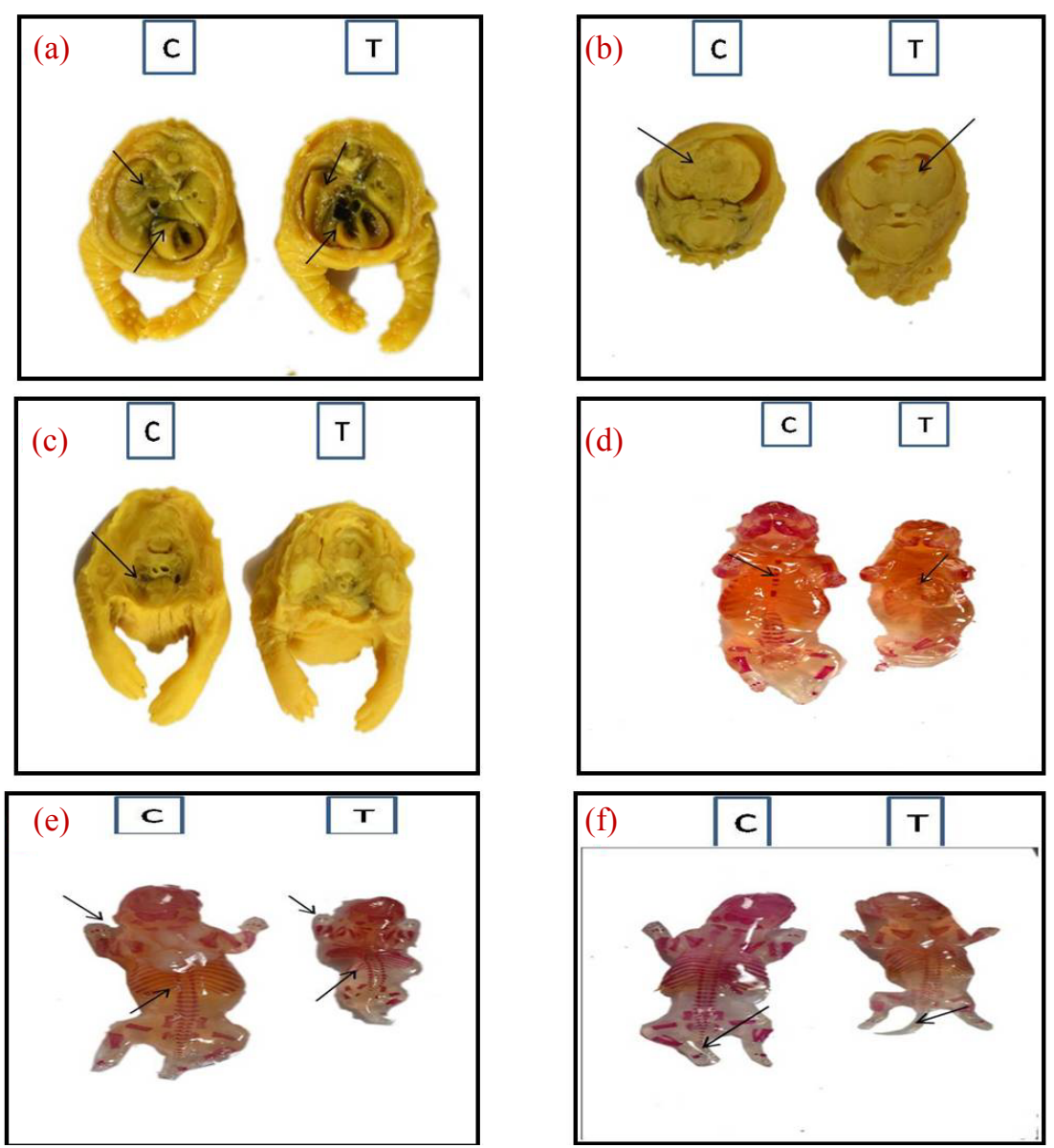

Figure 1. (a) Pulmonary hypoplasia with cardiac enlargement; (b)diverticulum dilatation; (c) thymus hypoplasia; (d) small size sternbrae; (e) absence of digit's bone of fore limb with rudentary ribs and (f) absence of caudal vertebrae of a fetuses obtained from pregnant rats after repeated oral administration of $200 \mathrm{mg}$ tilmicosin $/ \mathrm{kg} \cdot \mathrm{b} \cdot \mathrm{wt}$. from the 6 th to 15 th day of pregnancy. $\mathrm{C}$ represents (control group) and $\mathrm{T}$ represents treated group.

Table 3. Skeletal deformities in fetuses obtained from pregnant female rats after oral administration of 20,100 , and $200 \mathrm{mg}$ tilmicosin $/ \mathrm{kg} \cdot \mathrm{b} \cdot \mathrm{wt}$ from the 6 th to 15 th day of pregnancy once daily $(\mathrm{n}=10)$.

\begin{tabular}{ccccc}
\hline Parameters & 1st group & 2nd group & 3rd group & 4th group \\
\hline Number of examined fetuses & 24 & 24 & 24 & 24 \\
Skull & - & $2(8.33 \%)$ & $3(12.5 \%)$ & - \\
Sternbrea & - & $2(8.33 \%)$ & $4(16.66 \%)$ & - \\
Ribs & - & - & $1(4.16 \%)$ & - \\
Digital bone & - & $1(4.16 \%)$ & $3(12.5 \%)$ & - \\
Caudal vertebrae & - & $2(8.33 \%)$ & $3(12.5 \%)$ & - \\
\hline
\end{tabular}

$\%$ : percent of total abnormalities in relation to the number of examined fetuses.

Administration of tilmicosin at a dose $100,200 \mathrm{mg} / \mathrm{kg} \cdot \mathrm{b} \cdot \mathrm{wt}$ to female pregnant rats during the period of organogenesis induced many fetal visceral abnormalities as diverticulum dilatation in the brain of fetuses. The obtained result was consistent with [19] [20], after treatment with rapamycin induced enormous influences on early developmental period. This lesion might be attributed to the transfusion of arginine amino acid caused by tilmicosin or to the disturbance of the metabolism of arginine in fetus [19]. Arginine, an amino acid that is nutritionally 
essential for the fetus and neonate [21]. A significant nutritional problem in preterm infants is a severe deficiency of arginine (hypoargininemia), which results in cardiovascular, pulmonary, neurological, and intestinal dysfunction, arginine deficiency may contribute to the high rate of infant morbidity and mortality associated with premature births [22].

Pulmonary hypoplasia with cardiac enlargement due to tilmicosin administration at a dose of 100, $200 \mathrm{mg}$ which was a dose dependent may be attributed to disturbance of the metabolism of arginine in fetus [15]. Hypoargininemia results in cardiovascular, pulmonary dysfunction [22]. This is result agree with [23], who recorded that injection of tilmicosin $15 \mathrm{mg} / \mathrm{kg} \cdot \mathrm{b} \cdot \mathrm{wts}$ to lamb induce congenital defects. Also these results agree with [24], following administration of oleandomycin in rats. Injection of tilmicosin at $75 \mathrm{mg} / \mathrm{kg}$ bodyweight in single dose suggests that tilmicosin is cardiotoxic in mice [25].

Oral administration of tilmicosin at a dose $100,200 \mathrm{mg} / \mathrm{kg} \cdot \mathrm{b} \cdot \mathrm{wt}$ to female pregnant rats resulted in hypoplasia of thymus gland which was a dose dependent. Tacrolimus might impair thymic microenvironment and disturb the thymocyte maturation [26].

Impaired ossification of skull, absence of sternbrae, reduction or absence of caudalvertebrae, absence of digit's bone of fore and hind limb and absence of some metacarpal and metatarsal bone after administration of tilmicosin at dose 100 and $200 \mathrm{mg} / \mathrm{kg} \cdot \mathrm{b} \cdot \mathrm{wt}$ might be attributed to the disturbance in metabolism of some minerals as magnesium and zinc in fetus, or to the interference of the drug to the placental transmission of magnesium and zinc from the mother to the fetus [15].

Because of the negative relationship between Mg and PTH [27], an elevated Mg level may be a factor in the development of relative hypoparathyroidism, with inadequately low levels of PTH. This situation may lead to a low bone turnover state, with all its consequences with delayed calcium and phosphorus deposition into the bone matrix and elevation of serum levels of calcium and phosphorus, thus increasing the risk of metastatic calcification [28], This result agree with that reported by many investigators as [18], who study the teratogenicity tilmicosin in rabbits [29], who recorded the effect of rapamycin on bone growth in rabbits.

\section{Conclusion}

Administration of tilmicosin during period of organogenesis especially at high doses could induce some fetal defects and abnormalities, so it is advisable to avoid using during pregnancy.

\section{Conflicts of Interest}

The authors declare that there are no conflicts of interest.

\section{References}

[1] Lin, K.J., Mitchell, A.A., Yau, W.P., Louik, C. and Hernández-Díaz, S. (2013) Safety of Macrolides during Pregnancy. American Journal of Obstetrics and Gynecology, 208, 221-228. http://dx.doi.org/10.1016/j.ajog.2012.12.023

[2] Crider, K.S., Cleves, M.A., Reefhuis, J., Berry, R.J., Hobbs, C.A. and Hu, D.J. (2009) Antibacterial Medication Use during Pregnancy and Risk of Birth Defects: National Birth Defects Prevention Study. Archives of Pediatrics and Adolescent Medicine, 163, 978-985. http://dx.doi.org/10.1001/archpediatrics.2009.188

[3] Mitchell, A.A., Gilboa, S.M., Werler, M.M., Kelley, K.E., Louik, C. and Hernandez, S.D. (2011) Medication Use during Pregnancy, with Particular Focus on Prescription Drugs: 1976-2008. American Journal of Obstetrics and Gynecology, 205, 51-58. http://dx.doi.org/10.1016/j.ajog.2011.02.029

[4] Ose, E.E. and Tonkinson, L.V. (1988) Single-Dose Treatment of Neonatal Calf Pneumonia with the New Macrolide Antibiotic Tilmicosin. Veterinary Record, 123, 367-369. http://dx.doi.org/10.1136/vr.123.14.367

[5] Gorham, P.E., Carroll, L.H., McAskill, J.W., Watkins, L.E., Ose, E.E., Tonkinson, L.V. and Merrill, J.K. (1990) Tilmicosin as a Single Injection Treatment for Respiratory Disease of Feedlot Cattle. Canadian Veterinary Journal, 31, 826-829.

[6] Schumann, J.F., Janzen, E.D. and McKinnon, J.J. (1990) Prophylactic Tilmicosin Medication of Feedlot Calves at Arrival. Canadian Veterinary Journal, 31, 285-288.

[7] Heikkinen, T., Laine, K., Neuvonen, P. and Ekblad, U. (2000) The Transplacental Transfer of the Macrolide Antibiotics Erythromycin, Roxithromycin and Azithromycin. International Journal of Obstetrics and Gynaecology, 107, 770775. http://dx.doi.org/10.1111/j.1471-0528.2000.tb13339.x

[8] Somer, G.F. (1962) Thalidomide and Congenital Abnormalities. The Lancet, 1, 912-913. 
http://dx.doi.org/10.1016/S0140-6736(62)91943-8

[9] Rahilly, R.O. (2001) Human Embryology \& Teratology. 3rd Edition, Wiley-Liss, New York.

[10] Moore, K. (1988) The Developing Human. 4th Edition, WB Saunder, Philadelphia.

[11] Hassert, G.L., De Baecke, P.J., Kulesza, J.S., Traina, V.M., Sinha, D.P. and Bernal, E. (1973) Toxicological, Pathological, and Teratological Studies in Animals with Cephradine. Antimicrobial Agents and Chemotherapy, 3, 682-685. http://dx.doi.org/10.1128/AAC.3.6.682

[12] Macintyre, D.J., Chang, H.H. and Kaufman, M.H. (1995) Teratogenic Effects of Amniotic Sac Puncture: A Mouse Model. Journal of Anatomy, 186, 527-539.

[13] Barcellona, P., Fanelli, O. and Campana, A. (1977) Teratological Study of Etoperidone in the Rat and Rabbi. Toxicology, 8, 87-94. http://dx.doi.org/10.1016/0300-483X(77)90026-9

[14] Hayes, A.W. (1988) Principles and Method of Toxicology. 2nd Edition, Reven Press, New York.

[15] Tuchmann, H. (1975) Drug Effects on Fetus. ADIS Press, New York.

[16] Mossad, G.A.E.S., Ashraf, A.A.E.K. and Amany, A.A.E.M. (2014) Evaluation of Teratogenic Potentials and Tissue Residues of Tiamulin in Albino Rats. Nature and Science, 12, 100-105.

[17] Zhu, J.B., Wan, X.Y., Zhu, Y.P., Ma, X.L., Zheng, Y.W. and Zhang, T.B. (2010) Toxicity of Bryostatin-1 on the Embryo Fetal Development of Sprague-Dawley Rats. Birth Defects Research Part B, Developmental and Reproductive Toxicology, 89, 171-174. http://dx.doi.org/10.1002/bdrb.20229

[18] Noda, A. (1993) Teratogenicity Study of EL-870 (Tilmicosin Aqueous) in Rabbits by Gavage. Unpublished Study No. 91-001 from Research Institute for Animal Science in Biochemistry and Toxicology, Japan, Submitted to WHO by Lilly, Basingstoke, UK.

[19] Karabulut, A.K., Uysal, I.I., Acar, H. and Fazliogullari, Z. (2008) Investigation of Developmental Toxicity and Teratogenicity of Macrolide Antibiotics in Cultured Rat Embryos. Anatomia, Histologia Embryologia, 37, 369-375. http://dx.doi.org/10.1111/j.1439-0264.2008.00861.x

[20] Moriyama, Y., Ohata, Y., Mori, S., Matsukawa, S., Michiue, T., Asashima, M. and Kuroda, H. (2011) Rapamycin Treatment Causes Developmental Delay, Pigmentation Defects, and Gastrointestinal Malformation on Xenopus Embryogenesis. Biochemical and Biophysical Research Communications, 404, 974-978. http://dx.doi.org/10.1016/j.bbrc.2010.12.093

[21] Wu, G., Meininger, C.J., Knabe, D.A., Bazer, F.W. and Rhoads, J.M. (2000) Arginine Nutrition in Development, Health and Disease. Current Opinion in Clinical Nutrition and Metabolic Care, 3, 59-66. http://dx.doi.org/10.1097/00075197-200001000-00010

[22] Wu, G., Jaeger, L.A., Bazer, F.W. and Rhoads, J.M. (2004) Arginine Deficiency in Preterm Infants: Biochemical Mechanisms and Nutritional Implications. Journal of Nutritional Biochemistry, 15, 442-451. http://dx.doi.org/10.1016/j.jnutbio.2003.11.010

[23] Christodoulopoulos, G. (2009) Adverse Outcome of Using Tilmicosin in a Lamb with Multiple Ventricular Septal Defects. Canadian Veterinary Journal, 50, 61-63.

[24] Petrova, P. and Savitskaia, T.N. (1988) Prenatal Effect of Oleandomycin on the Development of the Immunogenesis Organs. Farmakologiia and Toksikologiia, 51, 85-86.

[25] Kart, A., Yapar, K. and Karapehlivan M.M.C. (2007) The Possible Protective Effect of L-Carnitine on Tilmicosin-Induced Cardiotoxicity in Mice. Journal of Veterinary Medicine Series A-Physiology Pathology Clinical Medicine, 54, 144-146. http://dx.doi.org/10.1111/j.1439-0442.2007.00897.x

[26] Takai, K., Jojima, K., Sakatoku, J. and Fukumoto, T. (1990) Effects of FK506 on Rat Thymus: Time-Course Analysis by Immunoperoxidase Technique and Flow Cytofluorometry. Clinical and Experimental Immunology, 82, 445-449. http://dx.doi.org/10.1111/j.1365-2249.1990.tb05469.x

[27] Navarro, J.F., Mora, C., Jiménez, A., Torres, A., Macía, M. and García, J. (1999) Relationship between Serum Magnesium and Parathyroid Hormone Levels in Hemodialysis Patients. American Journal of Kidney Diseases, 34, 43-48. http://dx.doi.org/10.1016/S0272-6386(99)70106-X

[28] Wei, M., Esbaei, K., Bargman, J. and Oreopoulos, D.G. (2006) Relationship between Serum Magnesium, Parathyroid Hormonr, and Vascular Calcification in Patients on Dialysis: A Literature Review. Peritoneal Dialysis International, 26, 366-373.

[29] Phornphutkul, C., Lee, M., Voigt, C., Wu, K.Y., Ehrlich, M.G., Gruppuso, P.A. and Chen, Q. (2009) The Effect of Rapamycin on Bone Growth in Rabbits. Journal of Orthopeadic Research, 27, 1157-1161. http://dx.doi.org/10.1002/jor.20894 